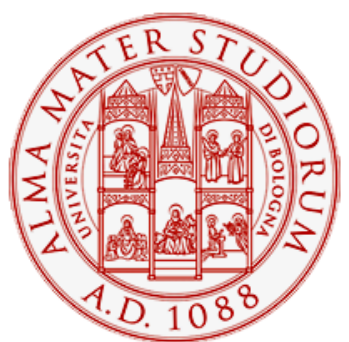

Alma Mater Studiorum - Università di Bologna DEPARTMENT OF ECONOMICS

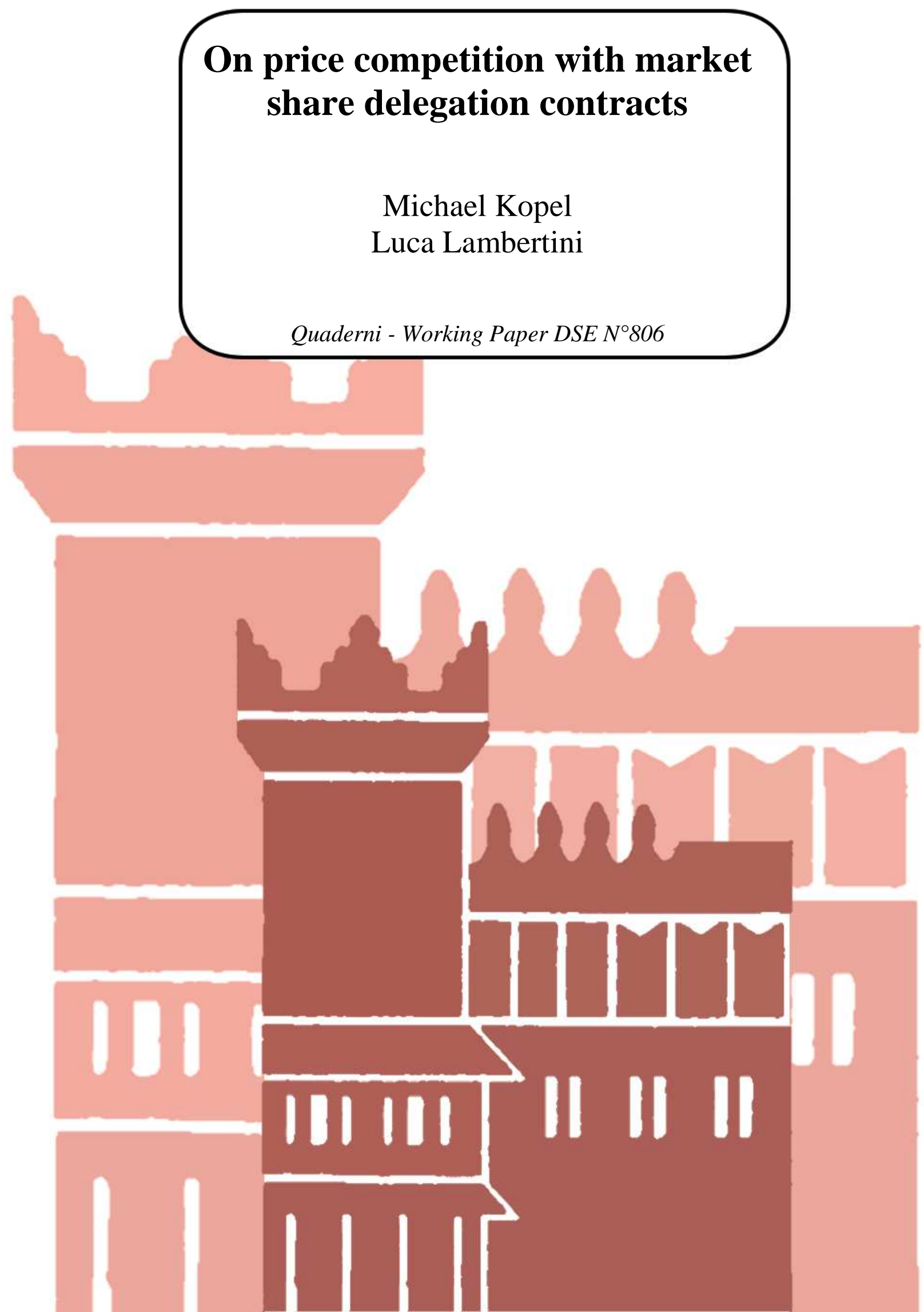




\title{
On price competition with market share delegation contracts
}

\author{
Michael Kopel ${ }^{\S}$ and Luca Lambertini ${ }^{\#}$ \\ $\S$ University of Graz \\ Institute of Organization and Economics of Institutions \\ Universitätsstraße 15/E4, 8010 Graz, Austria \\ michael.kopel@uni-graz.at \\ \# University of Bologna, Department of Economics \\ Strada Maggiore 45, 40125 Bologna, Italy \\ luca.lambertini@unibo.it
}

January 18, 2012

\begin{abstract}
We identify a mistake in the specification of the demand system used in the strategic delegation model based on market shares by Jansen et al. (2007), whereby the price remains above marginal cost when goods are homogeneous. After amending this aspect, we perform a profit comparison with the alternative delegation scheme à la Fershtman and Judd (1987).
\end{abstract}

JEL Codes: L13

Keywords: delegation, managerial firms, Bertrand competition 


\section{Introduction}

In a recent paper, Jansen, van Lier and van Witteloostuijn (2007, JLW henceforth) investigate the properties of Cournot and Bertrand behaviour in a strategic delegation model where contracts instruct managers to maximise a combination of profits and market shares. ${ }^{1}$ In this note, we single out a mistake in the specification of the market demand functions, that in JLW are modelled in such a way that the resulting prices do not collapse to marginal cost under full product substitutability. To amend this aspect, we properly define demands and work out the Bertrand case anew, and then proceed to compare the performance of firms against the alternative delegation scheme adopted by Fershtman and Judd (1987).

\section{The model}

Consider a differentiated duopoly where symmetric firms share the same marginal and average production cost $c \in[0,1)$. JLW set out to sketch the price competition case by adopting the demand system

$$
q_{i}=1-p_{i}+(1-\beta) p_{j}
$$

where $q_{i}$ and $p_{i}$ are firm $i$ 's quantity and price, respectively, and $\beta \in[0,1]$ measures the degree of differentiation, with homogeneous goods at $\beta=0$ and $\beta<1 / c$ (see JLW, 2007, p. 536). Before delving into the details of the

\footnotetext{
${ }^{1}$ There has been an increasing interest in strategic incentive models where managers are compensated based on profits and market shares, see e.g. Ritz (2008) and Wang and Wang (2010). In recent contributions, the performance of firms using such type of contracts for their managers has been compared to results obtained in the cases of sales, revenue, and relative profits, see Jansen et al. (2009), Manasakis et al. (2010) and, more general, Berr (2011). All these contributions - with the exception of Jansen et al. (2007), who briefly consider the price-setting model - focus on quantity competition.
} 
strategic delegation case, it is worth focussing the attention on the features of price competition based on (1) assuming firms are strict profit-seeking (entrepreneurial) units. The objective of owner $i$ is

$$
\max _{p_{i}} \pi_{i}=\left(p_{i}-c\right)\left[1-p_{i}+(1-\beta) p_{j}\right]
$$

requiring

$$
\frac{\partial \pi_{i}}{\partial p_{i}}=1+c-2 p_{i}+(1-\beta) p_{j}=0
$$

whereby the candidate symmetric equilibrium price is $p^{*}=(1+c) /(1+\beta)$, and the resulting per-firm output and profits are $q^{*}=(1-\beta c) /(1+\beta)$ and $\pi^{*}=(1-\beta c)^{2} /(1+\beta)^{2}=\left(q^{*}\right)^{2}$.

Now, if $\beta$ were indeed a direct measure of product differentiation, one should observe both price and profits monotonically increasing in $\beta$, while instead the opposite applies:

$$
\begin{gathered}
\frac{\partial p^{*}}{\partial \beta}=-\frac{1+c}{(1+\beta)}<0 \text { always; } \\
\frac{\partial \pi^{*}}{\partial \beta}=\frac{2(1+c)(\beta c-1)}{(1+\beta)^{3}}<0 \forall \beta<\frac{1}{c}
\end{gathered}
$$

and imposing $\partial \pi^{*} / \partial \beta>0$ would in turn imply $q^{*}<0$.

Moreover, under full substitutability, marginal cost pricing with zero profits should of course emerge, while setting $\beta=0$ yields $p^{*}=1+c>c$ and $\pi^{*}=1$. Also, note that $1+c>(1+c) / 2$, which implies that this model yields a duopoly price with homogeneous goods higher than full monopoly price. $^{2}$

The source of this issue is to be found in a mistaken normalization. This becomes apparent as soon as one, instead of (1), adopts the demand system

\footnotetext{
${ }^{2}$ The same problem, generated by an analogous demand structure, appears in Sklivas (1987, eq. (7), p. 455) and Miller and Pazgal (2001, p. 285), and also in Fershtman and Judd (1987, section 5).
} 
dating back to Bowley (1924) and then revived by Spence (1976), Dixit (1979) and Singh and Vives (1984), inter alia:

$$
q_{i}=\frac{a}{1+s}-\frac{b p_{i}}{1-s^{2}}+\frac{s p_{j}}{1-s^{2}}
$$

where $a>c, b>0$ and $s \in(-b, b)$, with parameter $s$ measuring the degree of substitutability (in the positive range) or complementarity (in the negative range) between goods. One can indeed define

$$
\frac{s}{1-s^{2}} \equiv 1-\beta
$$

but then the simultaneous normalization of $a /(1+s)$ and $b /\left(1-s^{2}\right)$ to one is altogether inadmissible, as $a /(1+s) \neq b /\left(1-s^{2}\right)$, and incompatible with (6).

Accordingly, in the remainder we will use (5), posing $a=b=1$ for the sake of simplicity. Now we proceed to the analysis of the two-stage duopoly game between managerial firms in the market share case.

The manager of firm $i$ is assigned the following objective function:

$$
M_{i}=\pi_{i}+\frac{w_{i} q_{i}}{q_{i}+q_{j}}
$$

where $w_{i}$ is the delegation variable to be chosen by the owner at the first stage. The first order conditions (FOC) at the market stage for $i=1,2$ are

$$
\frac{\partial M_{i}}{\partial p_{i}}=\frac{1+c-s-2 p_{i}+s p_{j}}{1-s^{2}}-\frac{w_{i}(1+s)\left(1-p_{j}\right)}{(1-s)\left(2-p_{i}-p_{j}\right)^{2}}=F_{i}\left(p_{i}, p_{j}, w_{i}, w_{j}\right)=0
$$

and solving this system would yield the Bertrand-Nash equilibrium prices in the form $p_{i}^{B N}\left(w_{i}, w_{j}\right)$. In order to obtain the expressions of prices, we proceed as JLW (2007, p. 534) do in the quantity space. First, consider the owner's FOC at the contract stage:

$$
\frac{\partial \pi_{i}}{\partial w_{i}}=\frac{\partial p_{i}}{\partial w_{i}}\left(\frac{1}{1+s}-\frac{2 p_{i}-c}{1-s^{2}}+\frac{s p_{j}}{1-s^{2}}\right)+\frac{s\left(p_{i}-c\right)}{1-s^{2}} \frac{\partial p_{j}}{\partial w_{i}}=0 .
$$


To obtain the partial derivatives $\frac{\partial p_{i}}{\partial w_{i}}$ and $\frac{\partial p_{j}}{\partial w_{i}}$, we differentiate the FOC (8) with respect to $w_{i}$ and $w_{j}$ taking into account that $p_{i}=p_{i}\left(w_{i}, w_{j}\right)$. The resulting linear system can be simply written as

$$
\underbrace{\left[\begin{array}{ll}
\frac{\partial F_{i}}{\partial p_{i}} & \frac{\partial F_{i}}{\partial p_{j}} \\
\frac{\partial F_{j}}{\partial p_{i}} & \frac{\partial F_{j}}{\partial p_{j}}
\end{array}\right]}_{=: F}\left(\begin{array}{c}
\frac{\partial p_{i}}{\partial w_{i}} \\
\frac{\partial p_{j}}{\partial w_{i}}
\end{array}\right)=-\left(\begin{array}{l}
\frac{\partial F_{i}}{\partial w_{i}} \\
\frac{\partial F_{j}}{\partial w_{i}}
\end{array}\right) .
$$

Applying Cramer's rule, the solutions can now be obtained as

$$
\frac{\partial p_{i}}{\partial w_{i}}=-\frac{1}{J_{F}} \Delta\left[\begin{array}{ll}
\frac{\partial F_{i}}{\partial w_{i}} & \frac{\partial F_{i}}{\partial p_{j}} \\
\frac{\partial F_{j}}{\partial w_{i}} & \frac{\partial F_{j}}{\partial p_{j}}
\end{array}\right], \quad \frac{\partial p_{j}}{\partial w_{i}}=-\frac{1}{J_{F}} \Delta\left[\begin{array}{ll}
\frac{\partial F_{i}}{\partial p_{i}} & \frac{\partial F_{i}}{\partial w_{i}} \\
\frac{\partial F_{j}}{\partial p_{i}} & \frac{\partial F_{j}}{\partial w_{i}}
\end{array}\right],
$$

where $J_{F}=\Delta F$ and $\Delta$ denotes the determinant of the corresponding matrix.

Inserting these expressions into (9) yields an additional condition which has to hold in equilibrium. If we now exploit the ex ante symmetry of the model and set $p_{i}=p_{j}=p$ and $w_{i}=w_{j}=w$, from (8) we obtain

$$
w=\frac{4(1-p)[1+c-s-p(2-s)]}{(1+s)^{2}} .
$$

Inserting this expression into the condition (9) and assuming symmetry, we obtain a quadratic polynomial with solutions

$$
p_{ \pm}=\frac{10-s(10-s)+c[6-s(2+s)] \pm(1-c) \sqrt{4-[8-s(4+s)] s^{2}}}{4(4-3 s)} .
$$

We have

$$
\begin{gathered}
\lim _{s \rightarrow 1} p_{+}=\frac{1+c}{2} ; \lim _{s \rightarrow 1} p_{-}=c \\
\lim _{s \rightarrow 0} p_{+}=\frac{3+c}{4} ; \lim _{s \rightarrow 0} p_{-}=\frac{1+c}{2}
\end{gathered}
$$


so that we take $p_{-}$as the only reasonable candidate equilibrium price. This is confirmed by looking at the corresponding individual output levels:

$$
q_{ \pm}=\frac{(1-c)\left[6-s(2+s) \pm \sqrt{4-[8-s(4+s)] s^{2}}\right]}{4(1+s)(4-3 s)}
$$

with

$$
\begin{aligned}
& \lim _{s \rightarrow 0} q_{+}=\lim _{s \rightarrow 1} q_{+}=\frac{1-c}{4} \\
& \lim _{s \rightarrow 0} q_{-}=\lim _{s \rightarrow 1} q_{-}=\frac{1-c}{2}
\end{aligned}
$$

A definitive element in favour of $p_{-}$is the stability analysis based on the determinant of the Jacobian matrix in the price space, revealing that

$$
\begin{aligned}
& \frac{\partial^{2} M_{i}}{\partial p_{i}^{2}}-\frac{\partial^{2} M_{i}}{\partial p_{i} \partial p_{j}}<0 \text { in } p=p_{+} \\
& \frac{\partial^{2} M_{i}}{\partial p_{i}^{2}}-\frac{\partial^{2} M_{i}}{\partial p_{i} \partial p_{j}}>0 \text { in } p=p_{-}
\end{aligned}
$$

whereby the solution $p_{-}$is stable while the other is not.

Now that we have obtained the correct solutions to the price-setting delegation game for the market share case, we may move on to compare the equilibrium price $p_{-}$obtained above with that characterising the incentive scheme used by Fershtman and Judd (1987, FJ henceforth). In the FJ case the objective of manager $i$ is ${ }^{3}$

$$
M_{i}=\alpha_{i} \pi_{i}+\left(1-\alpha_{i}\right) R_{i}
$$

$R_{i}=p_{i} q_{i}$ being the firm's revenues. We stick to our previous normalisation, $a=b=1$. From the FOCs in the price space one obtains

$$
p_{F J}=\frac{2\left(1+\alpha_{i} c\right)-s\left(1+s-\alpha_{j} c\right)}{4-s^{2}}
$$

\footnotetext{
${ }^{3}$ Thi is equivalent to the approach used by Vickers (1985). See the appendix in Lambertini and Trombetta (2002).
} 
Then, profit maximization at the first stage requires

$$
\alpha_{F J}=\frac{(1-s) s^{2}+c\left(2-s^{2}\right)(2-s)}{c\left[2(2-s)-s^{2}\right]}
$$

so that (17) simplifies as follows:

$$
p_{F J}=\frac{2(1-s)+c\left(2-s^{2}\right)}{4-s(2+s)}
$$

which of course belongs to the interval $[c,(1+c) / 2]$ for all $s \in[0,1]$. At this point a numerical excercise suffices to check that $p_{F J}<p_{-}$and consequently also that profits are lower under the FJ delegation scheme than under market share-based contracts for all $s \in(0,1)$. To sum up, this confirms the qualitative conclusion attained by JLW in comparatively assessing the market share-based incentive scheme against that of FJ.

\section{Conclusion}

In this note, we have shown that Jansen et al. (2007) use a misspecified demand system, and we have corrected their mistake. We have then derived the correct solution and compared it with the delegation game based on sales revenue which has been originally studied in Fershtman and Judd (1987). This has allowed us to point out that using contracts based on market share indeed makes competition softer and results in higher profits. 


\section{References}

[1] Berr, F. (2011), Stackelberg Equilibria in Managerial Delegation Games, European Journal of Operational Research, 212, 251-62.

[2] Bowley, A.L. (1924), The Mathematical Groundwork of Economics, Oxford, Oxford University Press.

[3] Dixit, A. (1979), "A Model of Duopoly Suggesting the Theory of Entry Barriers", Bell Journal of Economics, 10, 20-32.

[4] Fershtman, C. and K. Judd (1987), "Equilibrium Incentives in Oligopoly", American Economic Review, 77, 927-40.

[5] Jansen, T., A. van Lier and A. van Witteloostuijn (2007), "A Note on Strategic Delegation: The Market Share Case", International Journal of Industrial Organization, 25, 531-39.

[6] Jansen, T., A. van Lier and A. van Witteloostuijn (2009), On the Impact of Managerial Bonus Systems on Firm Profit and Market Competition: The Cases of Pure Profit, Sales, Market Share and Relative Profits Compared, Managerial and Decision Economics, 30, 141-53.

[7] Lambertini, L. and M. Trombetta (2002), "Delegation and Firms' Ability to Collude", Journal of Economic Behavior and Organization, 47, 359-73.

[8] Manasakis, C., E. Mitrokostas, and E. Petrakis (2010), Endogenous Managerial Incentive Contracts in a Differentiated Duopoly, With and Without Commitment, Managerial and Decision Economics, 31, 531-43.

[9] Miller, N.H. and A.I. Pazgal (2001), "The Equivalence of Price and Quantity Competition with Delegation", RAND Journal of Economics, 32, 284-301. 
[10] Ritz, R.A. (2008), "Strategic Incentives for Market Share", International Journal of Industrial Organization, 26, 586-97.

[11] Singh, N. and X. Vives (1984), "Price and Quantity Competition in a Differentiated Duopoly", RAND Journal of Economics, 15, 546-54.

[12] Sklivas, S.D. (1987), "The Strategic Choice of Managerial Incentives", RAND Journal of Economics, 18, 452-58.

[13] Spence, M. (1976), "Product Differentiation and Welfare", American Economic Review, 66, 407-14.

[14] Vickers, J. (1985), "Delegation and the Theory of the Firm", Economic Journal, 95 (Conference Papers), 138-47.

[15] Wang, L.F.S. and Y.-C. (2010), Input Pricing and Market Share Delegtion in a Vertically Related Market: Is the Timing Order Relevant? International Journal of the Economics of Business, 17, 207-21. 


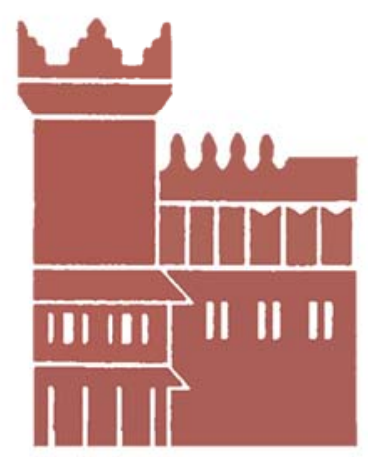

Alma Mater Studiorum - Università di Bologna DEPARTMENT OF ECONOMICS

Strada Maggiore 45

40125 Bologna - Italy

Tel. +39051 2092604

Fax +390512092664

http://www.dse.unibo.it 